\title{
PHILOSOPHISCHES WÖRTERBUGH
}

\author{
von \\ DR. MAX APEL \\ Fanfte, völlig neubearbeitete Auflage \\ von \\ DR. PETER LUDZ
}

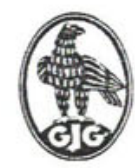

WALTER DE GRUYTER \& CO.

vormals G. J. Göschen'sche Verlagshandlung - J. Guttentag,

Verlagøbuchhandlung - Georg Reimer - Karl J. Trūbner - Veit \& Comp.

BERLIN 1958 


\section{(C)}

Copyright 1958 by Walter de Gruyter \& Co., Berlin W 35, Genthiner Straße 13. Alle Rechte, einschl. der Rechte der Herstellung von Photokopien und Mikrofilmen, von der Verlagshandlung vorbehalten. - Archiv-Nr. 111031. Satz und Druck: Paul Funk, Berlin W 35. - Printed in Germany. 